\title{
What is the prevalence of prostate cancer among men with low prostate-specific antigen levels?
}

Thompson IM, Pauler DK, Goodman PJ, Tangen CM, Lucia MS, Parnes $\mathrm{HL}$, et al. Prevalence of prostate cancer among men with a prostate-specific antigen level $\leq 4.0 \mathrm{ng}$ per milliliter. N Engl J Med 2004;350:2239-46.

Background: Screening for prostate cancer usually involves measuring prostate-specific antigen (PSA) levels and performing prostate biopsies if the PSA level is above a certain cutoff level (usually $4 \mathrm{ng} / \mathrm{mL}[\mu \mathrm{g} / \mathrm{L}]$ ). There has been no systematic assessment of the prevalence and clinical significance of prostate cancers detected at PSA levels below conventional cutoff levels.

Design: This study used patient data collected from the placebo arm of a large randomized, double-blind, placebo-controlled trial of finasteride for the primary prevention of prostate cancer. ${ }^{1}$ Men were enrolled if they were otherwise healthy, were aged 55 or more, had a PSA level of $3.0 \mu \mathrm{g} / \mathrm{L}$ or less, had a normal finding on digital rectal examination (DRE) and had no to moderate symptoms of prostatic hyperplasia. Participants were followed for up to 7 years and underwent annual PSA measurement and DRE. ㄱ During the study, subjects with either a PSA level above $4.0 \mu \mathrm{g} / \mathrm{L}$ or an abnormal DRE result underwent prostate biopsy. At the end of 7 years, all subjects who did not yet have a biopsy had one regardless of their PSA level. A total of 3568

Table 1: Prevalence of prostate cancer among men with prostate-specific antigen (PSA) levels $\leq 4.0 \mu \mathrm{g} / \mathrm{L}$

\begin{tabular}{lccc}
\hline & $\begin{array}{c}\text { No. (and \%) } \\
\text { with prostate } \\
\text { PSA level, } \\
\mu \mathrm{g} / \mathrm{L}\end{array}$ & $\begin{array}{c}\text { No. } \text { (and \%) } \\
n=2950\end{array}$ & $\begin{array}{c}\text { with high-grade } \\
\text { prostate cancer } \\
n=449\end{array}$ \\
\hline$\leq 0.5$ & 486 & $32(6.6)$ & $4(12.5)$ \\
$0.6-1.0$ & 791 & $80(10.1)$ & $8(10.0)$ \\
$1.1-2.0$ & 998 & $170(17.0)$ & $20(11.8)$ \\
$2.1-3.0$ & 482 & $115(23.9)$ & $22(19.1)$ \\
$3.1-4.0$ & 193 & $52(26.9)$ & $13(25.0)$ \\
\hline
\end{tabular}

men were eligible to undergo end-of-study biopsy, and 2950 $(83 \%)$ did so.

Results: Of the 2950 men who completed the trial, 449 (15.2\%) had prostate cancer detected at the end-of-study biopsy; of these, 67 (14.9\%) had highgrade disease, as defined by a Gleason score of 7-9 (Table 1). All diagnosed cancers with available stage information (93.3\%) were stage T1 (clinically localized, impalpable disease). The risk of prostate cancer increased with increasing PSA level, from $6.6 \%$ for levels of $0.5 \mu \mathrm{g} / \mathrm{L}$ or less to $26.9 \%$ for levels of 3.1 to $4.0 \mu \mathrm{g} / \mathrm{L}$ (odds ratio 1.66 per unit increase in PSA level, 95\% confidence interval 1.50-1.85).

Commentary: The introduction of PSA screening in the early 1980s radically transformed the diagnosis, treatment and followup of patients with prostate cancer. Despite being the most common internal malignant disease in men, the evidence in favour of prostate cancer screening remains controversial. ${ }^{2}$ In particular, using the conventional cutoff point of $4.0 \mu \mathrm{g} / \mathrm{L}$ to identify men who should undergo biopsy has been estimated to miss up to $82 \%$ of cancers in younger men and $65 \%$ of those in older men.

This well-designed analysis is the largest and most recent study to call attention to the poor performance of PSA measurement as a screening manoeuvre. Although $17 \%$ of eligible men did not undergo biopsy, this is unlikely to affect the 2 key messages from the study. First, the prevalence of prostate cancer was $15 \%$ in a group of men who were believed to be at very low risk of prostate cancer. Second, of those with cancer, a significant proportion harboured clinically important disease.

The findings of this study raise serious questions about the wisdom of the current strategy for prostate cancer screening. ${ }^{4}$ Absolute PSA cutoff levels, whether age-adjusted or not, appear to be of limited value in identifying men with clinically important prostate cancer. Better markers are needed. One possible approach that shows promise, to be validated in properly designed trials, involves monitoring the rate of rise of PSA (PSA velocity) over time. ${ }^{5}$

Practice implications: Despite the uncertainties, many clinicians and patients will continue to opt for prostate cancer screening. However, this study demonstrates that current screening practices are suboptimal. Better criteria than absolute PSA cutoff levels are needed to identify who should undergo biopsy. Adherence to current practice for prostate cancer screening will miss a significant number of cases.

\section{Shabbir M.H. Alibhai}

Division of General Internal

Medicine and Clinical Epidemiology

University Health Network

Toronto, Ont.

\section{References}

1. Thompson IM, Goodman PJ, Tangen CM, Lucia MS, Miller GJ, Ford LG, et al. The influence of finasteride on the development of prostate cancer. $N$ Engl F Med 2003;349(3):215-24.

2. Frankel S, Smith GD, Donovan J, Neal D. Screening for prostate cancer. Lancet 2003;361(9363):1122-8.

3. Punglia RS, D'Amico AV, Catalona WJ, Roehl KA, Kuntz KM. Effect of verification bias on screening for prostate cancer by measurement of prostate-specific antigen. $N$ Engl $7 \mathrm{Med}$ 2003;349(4):335-42.

4. Pound of prevention, ounce of cure? [editorial]. CMA7 2004;171(3):213.

5. D'Amico AV, Chen MH, Roehl KA, Catalona WJ. Preoperative PSA velocity and the risk of death from prostate cancer after radical prostatectomy. $N$ Engl 7 Med 2004;351(2):125-35. 